\title{
AMERICAN BOARD OF THORACIC SURGERY: CHANGES IN THE RECERTIFICATION REQUIREMENTS EFFECTIVE IN THE YEAR 2001
}

American Board of Thoracic Surgery



n 1976, the American Board of Thoracic Surgery first issued time-limitcd certificates. Ten years later, these certificates expired and the annual recertification process began. The requirements for recertification remained unchanged for the ensuing 22 years. The directors of the Board recently reviewed these requirements in light of the many changes in the health care industry and the credentialing requirements of hospitals and third-party payers. The Board also compared its recertification policies with those of other American Board of Medical Specialties members. As a result of this review, changes in the American Board of Thoracic Surgery recertification policy will be implemented in the year 2001.

A valid American Board of Thoracic Surgery certificate will be an absolute requirement for entering the recertification process in the year 2001 . However, Diplomates who have allowed their certificates to lapse will be able to recertify in 1999 and 2000 under the current policy. Beginning in 2001, the only pathway for renewal of an invalid certificate will be to take and pass the Part I (written) and the Part II (oral) examinations. The continuing medical education requirements beginning in the year 2001 will also change. The new requirement will be 70 Category I credits in either cardiothoracic surgery or

Copyright (c) 1998 by Mosby, Inc.

$0022-5223 / 98 \$ 5.00+0 \quad \mathbf{1 2 / 1 / 9 2 4 9 0}$ general surgery earned during the 2 years prior to applying for recertification. However, not all Category I credits will be allowed; for instance, SESATS and SESAPS are the only self-instructional materials acceptable for CME credit. The Physicians Recognition Award for recertifying in general surgery will not be accepted in fulfillment of the CME requirement. Other specific CME requirements will be published in the Recertification Booklet of Information.

In 2001, the American Board of Thoracic Surgery will no longer publish the names of individuals who have not recertified. Listing Diplomates with invalid certificates in directories published by the American Board of Medical Specialties has proven to be confusing to credentialing groups of various hospitals, managed care providers, and patients seeking care. In addition, none of the other 24 member boards of the American Board of Medical Specialties publishes in the directories the names of individuals holding invalid certificates.

The Board is communicating this information to all Diplomates to allow time for those who hold an invalid certificate to recertify during the next 2 years. Additionally, all Diplomates should be aware of the changes in the requirements in anticipation of renewing their own certificates. The Board feels that recertification is important to the public and to each physician's professional career. 